\title{
IDENTIDADE E PLURALIDADE CULTURAL EM LIVROS DIDÁTICOS DE ESPANHOL PRODUZIDOS NO BRASIL E SELECIONADOS PELO PNLD - PROGRAMA NACIONAL DO LIVRO DIDÁTICO
}

\section{Jeferson Mundim de SOUZA*}

- RESUMO: O presente artigo pretende promover, diante da atual realidade, na qual se configura um cenário marcado pelo rompimento de fronteiras culturais e por se entender o mundo como um universo mais unificado, refletir sobre as concepçóes de cultura existentes nesse contexto. $\mathrm{O}$ mundo cada vez mais marcado pela multiculturalidade das sociedades, pelo enfraquecimento de antigos referenciais culturais e pela multiplicação de afirmações identitárias. $\mathrm{O}$ ensino de línguas estrangeiras é uma oportunidade para inserir o aluno nesse universo planetário de uma aparente cultura on-line, mas que, cada vez mais, vem reforçar identidades diversas. Nesse sentido, o artigo aqui apresentado, além de promover espaço para uma discussão acerca dessas questóes próprias da contemporaneidade, apresenta as análises de uma pesquisa feita com dois, dos quatro livros didáticos de espanhol, selecionados para integrarem o Programa Nacional do Livro para o Ensino Médio, delimitando a escolha às características de tempo e espaço para análise e construção desse escrito: El arte de leer Español e Síntesis: curso de língua española. Não serão apresentadas as análises totais dos livros, optando por fazer um recorte, tomando como critério algumas Unidades didáticas e atividades propostas mais direcionadas ao tema, além de poder atender as regras e brevidade desse artigo. A referida pesquisa versou sobre as seguintes questóes: De que forma os manuais didáticos para o ensino- aprendizagem de espanhol produzido no Brasil contempla: a) a pluralidade cultural do mundo hispânico? ; b) a afirmação - com respeito a sua formação em comunidade e do convívio da (s) identidade (s) latina- americana(s)? ; e c) a interaçáo - proposta a partir das estratégias de aprendizagem, com a formação identitária do aluno brasileiro? Para tanto, adotamos a metodologia da análise qualitativa e a técnica de análise de conteúdo, tomando como indicadores de análise as seguintes categorias: espaços geográficos e territórios culturais explorados nos textos; as identidades dos personagens anônimos e famosos que circulam nos livros; e as atividades didáticas relacionadas às questóes culturais propostas aos alunos. A partir das análises pode- se concluir que os livros selecionados dão diferentes respostas às questôes propostas para esta pesquisa. O livro Síntesis: curso de lengua española, não explora, de fato, a pluralidade cultural do mundo hispânico; tem seus personagens marcados por identidades não latino-americanas e não promovem através das atividades relacionadas a

* PMSFCONDE - Prefeitura Municipal de São Francisco do Conde. Secretaria de Educação. Educação Básica. São Francisco do Conde - BA - Brasil. 43900-000 - jefersonmundim@gmail.com 
questôes culturais, nenhuma interação com a formação identitária do aluno brasileiro. Ao passo que, o livro El arte de leer Español explora a multiplicidade de espaços geográficos e territórios culturais do mundo hispânico, além de trazer referenciais do Brasil e de outros lugares. Além disso, o livro prioriza identidades latino-americanas e promove, em muitas atividades, a interação com as culturas e identidades dos aprendizes brasileiros de espanhol.

- PALAVRAS-CHAVE: Espanhol língua estrangeira. Identidade. Pluralidade cultural. Livro didático.

\section{Introdução}

O ensino de uma língua estrangeira ou segunda língua (LE e L2) não é uma preocupação recente. Em sua constituição histórica, vários foram os caminhos metodológicos indicados para que o processo de ensino-aprendizagem de um idioma, até então estrangeiro, ocorresse de forma efetiva, o que significa, dentre outras coisas, ir além da aprendizagem de estruturas gramaticais da língua, na tentativa de se construir outra identidade cultural, não substitutiva daquela própria do aprendiz, mas de outras possibilidades que se apresente na relação social com o outro.

A produção científica nesta área é de grande importância por contribuir para a ampliação da percepçáo de como o homem contemporâneo se relaciona socialmente. Diante da atual realidade na qual se configura um cenário marcado pelo rompimento de fronteiras culturais e por se entender o mundo como um universo mais unificado, faz-se necessário refletir as concepçóes de cultura existentes nesse contexto. "Na esfera cultural, a globalização não pode ser associada à ideia de homogeneização e, apesar dos novos valores e legitimaçôes" (ORTIZ, 1994, p. 18), o mundo está cada vez mais marcado pela multiculturalidade das sociedades, pelo enfraquecimento de antigos referenciais culturais e pela multiplicação de afirmações identitárias.

Por conseguinte, há, no Brasil, muitos estudos feitos os quais se referem à abordagem cultural no processo de ensino-aprendizagem de LE. Esses estudos ressaltam a relevância dos estudos culturais no direcionamento para desestrangeirizar (ALMEIDA FILHO, 2002) a língua que se aprende; a língua do estrangeiro, e nesse sentido, entender a cultura como via de acesso a uma LE não significa, em absoluto, oferecer aos alunos blocos de conteúdos gramaticais com pinceladas de referências culturais - quase sempre carregadas de estereótipos - para preencher as seçóes destinadas aos conteúdos culturais.

Talvez tenha sido bem acertado e considerável, que, para melhorar a compreensão das questóes de ensino-aprendizagem sobre conteúdos culturais, identitários em língua espanhola, está inserida a aprendizagem deste idioma no Brasil - marcada pela oferta obrigatória dessa língua nos currículos da educação básica (Lei 11.161/2005) - esta pesquisa também ganha força pela oportunidade de se analisar a produção editorial brasileira destinada ao ensino do referido idioma (BRASIL, 2005). 
As últimas décadas revelam, no ensino das LE, as concepções de uma abordagem mais aberta a entender que a aprendizagem de uma língua não se limita a estudos formais marcados por uma postura tradicional. Como merece destaque, os enfoques comunicativos - caracterizados por um ideal de contextualização e interaçáo introduzem, a partir dos anos 80, no Brasil, a concepçáa de um processo de ensinoaprendizagem significativo que entende a língua como uma realidade essencialmente variável capaz de promover a socializaçáo dos sujeitos.

Isso mostra que estudar uma LE, teórica e metodologicamente, não é mais concebido como forma de autoritarismo e subserviência político-ideológicos. Dessa forma, a abordagem cultural - proposta que entende a cultura como elemento indissociável dos estudos da língua estrangeira - se mostra presente nas apresentaçôes dos manuais didáticos e nos discursos de autores que pretendem rever o tratamento para questóes culturais e promover um olhar crítico sobre a cultura do outro numa tentativa de aprender com outras identidades culturais e aplicar a dos seus aprendizes. No entanto, na prática, a proposta de uma abordagem cultural ainda é incipiente e marcada por equívocos e propostas didáticas que não traduzem uma postura crítica frente a contatos interculturais, como é o caso das várias concepçôes de cultura, dos obstáculos comunicativos, das hierarquias e padróes sociais e das diferenças econômicas.

O "cantinho da cultura" (espaço reserva pelos autores dos livros didáticos para dizer que estão trabalhando com a abordagem intercultural) foi criado e durante muito tempo apareceu [ou ainda aparece?] no final dos manuais didáticos, geralmente carregados de ilustraçóes, músicas, poemas, curiosidades e outros elementos que, na maioria das vezes, só se limitam a apresentar um produto cultural do mundo estrangeiro.

Além dessa visão totalmente desprovida de um posicionamento crítico-reflexivo, pode-se acrescentar que esses elementos culturais apresentados quase sempre foram marcados por valores culturais hegemônicos e/ou estereotipados, o que contribui para um olhar equivocado e/ou preconceituoso sobre o outro ou até mesmo sobre si.

Ensinar-aprender uma LE deve ir além das informaçóes e práticas do conhecimento relacionado a aspectos fonético-fonológicos, morfológicos, sintáticos e semânticos; ensinar uma língua-cultura estrangeira é promover interaçôes sociais, trocas de informaçóes e conhecimentos das realidades culturais em contato.

Ao discutir a função que tem o aprendizado de uma LE, Coracini (2007, p. 152) destaca o papel desta no universo contemporâneo marcado pelo discurso da globalização, porém vai mais além em suas reflexôes ao considerar que:

A língua chamada estrangeira tem uma função formadora, atuando diretamente na imagem de nós mesmos e dos outros, na constituiçáo identitária do sujeito do inconsciente. Ainda que seja aprendida com um fim meramente utilitarista, ela traz sempre consigo consequências profundas e indeléveis para a constituição do sujeito: serão sempre outras vozes, outras culturas, outra maneira de organizar o pensamento; outro modo de ver o mundo e o outro. Vozes que se cruzam e se entrelaçam no 
inconsciente do sujeito, provocando reconfiguraçôes identitárias, rearranjos subjetivos, novos saberes - não tão novos para serem originais nem tão velhos que não possam ser criativos.

Nesse sentido, é importante destacar o trabalho com a identidade que envolve a construção de noçóes de continuidade e de permanência, sendo fundamental a consciência do aprendiz para sua percepção que identificará o eu e o nós sendo distintos e compreendendo em seu tempo esses processos. Ao mesmo tempo, a compreensão de que o outro é, simultaneamente, aquele que nos oferece a oportunidade de conhecer suas construçóes de identidade e espaços culturais, onde podemos aprender com ele e através dele, as diferenças vividas que podem suscitar em cada um, novos olhares, saberes e desconstruçóes diante de aspectos comparativos e relacionais, oferecendo a cada um o conhecimento sobre si mesmo e sobre grupos que mediante a aprendizagem de uma LE deve trazer oportunidade para que, neste intercâmbio intercultural, haja reconfiguraçóes identitárias e rearranjos subjetivos.

\section{Caminhos a partir das perguntas}

Considerando os avanços no que se refere a uma reflexão mais crítica quanto à abordagem cultural no ensino de LE, bem como a importância que o espanhol vem ganhando no Brasil, nos propomos a verificar como as questóes relativas aos conteúdos culturais vêm sendo tratadas no ensino deste idioma no país. De forma mais concreta, nossa pesquisa parte dos seguintes questionamentos: de que forma os LD para o ensinoaprendizagem de espanhol produzidos no Brasil contemplam: a pluralidade cultural do mundo hispânico; a afirmação da (s) identidade (s) latino-americana (s); e a interação com a formação identitária do aluno brasileiro?

No intuito de buscarmos responder às questôes de pesquisa aqui apresentadas, verificamos, nos livros selecionados, a presença dos espaços geográficos e dos territórios culturais que são apresentados; também lançamos um olhar investigativo em torno das identidades de famosos e anônimos que circulam nestes espaços e, finalizando, observamos se as atividades que são propostas nestes livros promovem a inter-relação cultural entre a cultura do universo hispânico e a do aluno brasileiro.

\section{Escolha de métodos}

Adotamos a metodologia da análise qualitativa e a técnica de análise de conteúdo, tomando como indicadores de análise as categorias: espaços geográficos e territórios culturais explorados nos textos; as identidades dos personagens anônimos e famosos que circulam nos livros e as atividades didáticas relacionadas às questóes de pluralidades culturais e interaçóes identitárias propostas aos alunos. Não serão apresentadas as análises totais dos livros, optando por fazer um recorte, tomando como critério algumas 
Unidades didáticas e atividades propostas mais direcionadas ao tema, além de poder atender as regras e brevidade desse artigo.

Em nosso caso, por trabalharmos com análise de livros didáticos, utilizamos a análise de conteúdos como técnica de pesquisa mais adequada. Berelson (apud NASCIMENTO, 2002) define a análise de conteúdo como - uma técnica de investigação que, através de uma descrição objetiva, sistemática e quantitativa do conteúdo manifesto das comunicações, tem por finalidade a interpretação destas mesmas comunicaçóes.

\section{Reflexões sobre cultura e identidade}

Os conceitos desenvolvidos ao longo da história sobre cultura e identidade, variam adequando-se a cada direcionamento e necessidade. Mas, em nosso caso específico, necessitamos de conceitos que se tornem práticas em nosso exercício do ensinoaprendizagem da língua espanhola através de materiais didáticos elaborados para esse fim. Portanto, segundo Authier-Revuz (apud CORACINI, 2007, p. 158):

Nós, professores e alunos, náo estamos preparados para compreender que ensinar uma língua estrangeira é oferecer experiências de estranheza, provocar situaçôes de estranhamento nas quais, por um momento, não somos capazes de nos reconhecer e, por vezes, de reconhecer o outro (e, portanto, de compreendê-lo); situaçóes que provocam confrontos internos, contradiçôes e conflitos que resultam do trabalho do inconsciente, trazendo deslocamentos pela aceitação do outro, da diferença, da náo-coincidência de si consigo mesmo, de si com os outros, do que se diz e do que se tem intenção de dizer.

A citação anterior corrobora para o encaminhamento de nossa análise sobre as propostas trazidas pelos autores, em seus livros didáticos, quando "desrespeitam" a formação do professor, que mesmo tendo em mãos materiais com abordagens identitárias e interculturais, ainda assim, os utiliza ignorando esses aspectos, talvez por falta de formação, apresentando ao alunado apenas conteúdos gramaticais tradicionais aprendidos na faculdade, bem como total distanciamento das realidades entre Espanha e países hispanofantes. A eles lhes parece estranho perceber no outro e com o outro, realidades tâo diferentes e ao mesmo tempo táo próximas, capazes de aprender e realizar trocas que muito colaboraria para o ensino de LE em abordagem intercultural e identitária.

Pensando sobre o envolvimento do professor e do aluno sobre seu aprendizado na perspectiva intercultural, atualmente, falar em cultura é assunto que está sempre em destaque nos diversos campos de estudo. Da mesma forma, falar em pluralidade ou multiplicidade, diversidade e identidade cultural é objeto de interesse não só de estudiosos do universo acadêmico, mas também de diversos setores da sociedade que se dizem interessados em discutir estas questóes. Apesar de o termo pluralidade cultural 
estar em destaque, no título desta pesquisa, entendemos que, quando se discute questóes que envolvem o universo cultural é inevitável não falar também em identidade e diversidade.

Portanto, ainda no intuito de trazer uma definição do que representa a pluralidade cultural numa sociedade, nos reportamos a Silva (2000, p. 100-101) que, ao tratar das questôes da identidade e da diferença na perspectiva dos estudos culturais, estabelece um paralelo entre a multiplicidade e a diversidade:

Tal como na matemática, o múltiplo é sempre um processo, uma operação, uma ação. A diversidade é estática, é um estado, é estéril. A multiplicidade é ativa, é um fluxo, é produtiva. A multiplicidade é uma máquina de produzir diferenças - diferenças que são irredutíveis à identidade. A diversidade limita-se ao existente. A multiplicidade estende e multiplica, prolifera, dissemina. A diversidade é um dado - da natureza ou da cultura. A multiplicidade é um movimento. A diversidade reafirma o idêntico. A multiplicidade estimula a diferença que se recusa a se fundir com o idêntico.

Neste sentido, a multiplicidade, termo usado por Silva, é considerado pelo autor como um processo dinâmico responsável por estimular as diferenças dentro deste universo múltiplo. De forma mais prática, a multiplicidade é responsável pela formação de uma concepção mais voltada para perceber o mundo dentro de uma ótica multicultural, o qual pode ser representado por uma variedade de vozes e discursos. Entendida dessa forma, a concepção que defende a ideia de cultura no plural está pautada na possibilidade de uma pluralidade de culturas, de diversos sistemas de referência e de significados variados e heterogêneos entre si.

Não se pode falar em diversidade cultural sem que, implicitamente, não se fale em identidade cultural, termo que cada autor disponibiliza um conceito, tentando definir as proximidades e distâncias sobre ele.

Hall (2005) apresenta três concepçóes de identidade: a) a partir da visão do sujeito do Iluminismo; b) do sujeito sociológico; c) e do sujeito pós-moderno. Nesse sentido, entender a identidade cultural na pós-modernidade é considerar os traços que marcam este sujeito não possuidor de uma identidade fixa, essencial ou permanente. Para Hall (2005, p. 13, grifo do autor), "O sujeito assume identidades diferentes em diferentes momentos; identidades que não são unificadas ao 'eu coerente'." No entanto, o sujeito do Iluminismo acreditava numa concepçáo individualista acerca do homem e de sua identidade. Nessa perspectiva, o homem, indivíduo centrado e unificado, era dono de uma identidade fixa e uniforme. Além disso, Hall ainda destaca o homem sociológico como sendo um indivíduo formado a partir das suas relaçóes com outros indivíduos, em sua vida social. Não sendo um ser autônomo, sua identidade é construída por meio de processos de interação com outros indivíduos do seu mundo.

Nesse sentido, Woodward define duas formas diferentes de se entender a identidade cultural: uma que reflete a busca para recuperar a verdade sobre o passado na unidade de 
uma história e de uma cultura partilhada; e outra, a segunda, mais simpática aos olhos de Hall, pautada no — tornar-se.

A posição de Hall enfatiza a fluidez da identidade. Ao ver a identidade como uma questão de 'tornar-se', aqueles que reivindicam a identidade não se limitaria a ser posicionados pela identidade: eles seriam capazes de posicionar a si próprios e de reconstruir e transformar as identidades históricas, herdadas de um suposto passado comum. (WOODWARD, 2000, p. 28).

Vista desta forma, as identidades são sempre flutuantes; elas resgatam, fazem-se e refazem-se por meio de um dinâmico processo de ressignificação contínua, através do qual, ao contrário do que geralmente pensamos, não estão em jogo apenas traços convergentes de indivíduos e grupos, mas, justamente em oposição, estão em jogo diferenças, aspectos que, marcando o que náo somos nos ajudam a entender o que somos. Assim, o que nos produz a sensação de brasilidade, que constrói a nossa identidade, não são apenas os elementos que internamente nos aproximam, mas, mais que isso, o que nos marca como brasileiros é o que nos faz diferentes de outros. Para Woodward, as identidades são fabricadas por meio da marcação da diferença. Essa marcação ocorre tanto por meio de sistemas simbólicos de representação quanto por meio de formas de exclusão social.

\section{O lugar da cultura e da identidade no Ensino de Língua Estrangeira - ELE}

Aprender outra língua-cultura é entrar em contato com outros saberes, outras formas de ser e de agir, e por isso, este processo é muito mais significativo do que por vezes o fazemos. Coracini (2007, p. 152) defende que "A língua chamada estrangeira tem uma função formadora atuando diretamente na imagem de nós mesmos e dos outros, na constituição identitária do sujeito do "inconsciente."

Coracini não despreza a função utilitária deste aprendizado, mas acrescenta que, além desta função, a aprendizagem de outra língua pode trazer outras significações para o aprendiz, significaçôes estas que podem mexer com estruturas profundas da subjetividade do sujeito. A autora defende que:

Ainda que seja aprendida com um fim meramente utilitarista, ela traz sempre consigo consequências profundas e indeléveis para a constituição do sujeito: serão sempre outras vozes, outras culturas, outras maneiras de organizar o pensamento, outro modo de ver o mundo e o outro, vozes que se cruzam e se entrelaçam no inconsciente do sujeito, provocando reconfiguraçōes identitárias, rearranjos subjetivos do sujeito, novos saberes - não tâo novos para não serem originais nem tấo velhos que não possam ser criativos. (CORACINI, 2007, p. 152). 
Não podemos deixar de destacar que a língua materna (LM) tem uma contribuição significativa para esse possível mal-estar que pode ser gerado por todo este processo de rearranjos e reestruturaçôes do eu identitário do sujeito em oposição ao ele, que marca a língua deste outro, a qual, neste processo de ensino-aprendizagem passa a ser nossa. A língua-cultura - na comunicação, vem buscando respostas para as dúvidas de como as pessoas conseguem compreender umas às outras quando náo possuem as mesmas experiências culturais, que é do estrangeiro, passa a ser a língua-alvo do aprendiz e, nesse jogo de interconexôes, não há como não haver, em alguns momentos, conflitos entre o eu e o ele, mesmo que, por vezes, não perpassem o campo do inconsciente. Ainda sobre esta experiência, Coracini (2007, p. 153) “[...] demonstra que há fortes hipóteses que tentam explicar a resistência inconsciente ao aprendizado de uma língua estrangeira pelo medo da perda da identidade."

Ainda no que se refere às fundamentaçóes teóricas deste trabalho, para que se possa entender como, de fato, as questôes culturais são tratadas na maioria dos LD de LE, Tilio (2006, p.125-126) destaca que:

Os livros didáticos se propóem a transmitir, de acordo com suas apresentaçóes, introduçóes e manuais do professor, aquilo que chamam de conhecimento cultural relevante. Entretanto, em geral, não tratam cultura seriamente, ou seja, de forma a levar os alunos a pensar criticamente. Tratar de questôes culturais na maioria dos livros significa apenas mencionar o estereótipo, nada mais do que falar dos hábitos, costumes, e comida do grupo cultural da língua estrangeira ensinada, muitas vezes perpetuando até certos preconceitos [...].

Não diferente de outras disciplinas, no caso do espanhol, sabe-se que o LD tem um papel importante no sistema educacional e, para o professor, este serve como apoio ou mesmo a única fonte de que ele dispóe para organizar-se não só na construçáo do seu plano de curso e na estruturação das suas aulas, como também na elaboração de exercícios e provas. Isso pode ser percebido e comprovado por nós em muitas das escolas que visitamos em supervisão de estágio de alunos de graduação em Letras.

No intuito de melhor estruturar a apresentação dessas análises, primeiramente trabalhamos apenas com o livro El arte de leer español (PICANÇO; VILLABA, 2006), em todas as categorias e, em seguida, passamos para o livro Sintesis: curso de lengua española (MARTIN, 2005), considerando os mesmos critérios. Elaboraremos uma descrição comparativa a partir dos enfoques descritos abaixo entre os dois livros, apresentando as respostas às nossas investigaçóes, tendo como base algumas atividades e Unidades didáticas aqui apresentadas, a fim de que possamos delinear as considerações finais vinculadas às perguntas de partida da pesquisa. 


\section{Primeiro Enfoque - El Arte de Leer Español}

Foco A: espaços geográficos e territórios culturais

O livro El Arte de leer Español, no que tange à exploração de espaços geográficos e territórios culturais, é bastante variado, pois, de forma geral, não se restringe aos centros de Madri ou de outros espaços de prestígio político-econômico. Este livro, diferente de todos os que já vimos enquanto professores de ELE, nos convida, em cada uma das suas unidades, a um passeio pelo universo geográfico- cultural hispânico. $\mathrm{O}$ mais interessante disso é que, também ao contrário de outros materiais, essa viagem em nada tem a ver com atitudes ensaiadas de turistas que vão a algum país hispânico e que, por isso, querem aprender costumes e hábitos da cultura estrangeira.

No decorrer desta análise, veremos como este livro constrói o mapa cultural do mundo hispânico. Observemos a seguir, o poema "Cantar a los niños latinoamericanos y caribenhos" (PICANÇO; VILLABA, 2006, p. 13.), texto que integra a primeira unidade do livro, intitulada Identidad:

Iba el niño corriendo por la selva, Corre corre por puertos y por calles, Por llanuras, montañas y por valles,

Por los ríos, el sol, la cordillera. Lleva, lleva en sus manos un poema De una punta a la otra de los Andes, Mientras busca a su hermano de los mares, Borrando las fronteras, las fronteras. Muchacho que llevaba entre sus brazos Un pedazo de sueño, de un gran sueño, Un pedazo de sueño, de un gran canto. ¡Qué se hace verdad en el momento En que unidos hermanos con hermanos Se funden en un beso, en un gran beso!

O texto da poetisa cubana Julia Calzadilla, além de trazer para a sala de aula espaços latino-americanos e caribenhos, não comuns nos livros com os quais já tivemos contato, traz a ideia de espaços variados que se caracterizam por elementos como selvas, ruas, montanhas, vales e rios, além da cordilheira (Andes) que deixa de ser, aqui, mero aspecto geográfico e assume seu lugar como território cultural. O correr de uma ponta a outra dos Andes e levar consigo o sonho de romper as fronteiras e unir os irmãos, pode ser também o intuito de percebermos os espaços, que hoje não são mais estanques e habitados por pessoas indiferentes às demais. Nessa ótica, o livro manifesta, já na sua primeira unidade, uma sensibilidade para perceber e explorar espaços e territórios dantes esquecidos ou subjugados a outros espaços e territórios como as grandes metrópoles. 
Em uma análise mais detalhada, poderíamos investigar a predominância de autores provenientes de espaços mais centrais ou periféricos. No caso do poema que acabamos de ler, notamos que o mesmo dá visibilidade a uma autora cubana, o que certamente demonstra a intenção das autoras do livro em trazer para este material não só escritores já consagrados e oriundos de zonas de prestígio internacional.

Complementando o texto apresentado, num contexto oportuno ainda para se discutir a identidade cultural, encontramos um mapa da América Latina, seguido de uma relação de países onde o espanhol é a língua materna. Ao lado, em tamanho bem menor do que normalmente aparece nos livros tradicionais, visualizamos um mapa da Espanha. O que nos chama a atençáo neste primeiro momento (considerando a imagem) é que, além de localizar países hispano- americanos, o aluno é levado a pensar na relação de proximidade entre o latino- americano e o brasileiro da mesma forma em que a Espanha perde lugar de destaque nesse cenário. Ademais, na mesma seção de atividades, o livro sugere que o aluno investigue a presença de línguas, consideradas minoritárias, localizadas em diversas regióes da Espanha, além de chamar a atenção para as línguas esquecidas que sobrevivem no território latino-americano. Nesse sentido, o livro expande a consciência multicultural do aluno, chegando até a sugerir uma discussão sobre o papel social que o Brasil representa no universo hispânico.

A Unidade de número 12, intitulada Fiestas y tradiciones, podemos perceber, por meio das diversas manifestaçóes culturais que são apresentadas, a pluralidade de espaços que são explorados. Iniciando a unidade com a passagem do Ano Novo, o texto Formas de celebrar según las culturas (PICANÇO; VILLABA, 2006, p. 194), nos coloca em contato não só com o universo hispânico, mas também faz referência a outros países onde a celebração dessa festa é uma tradição.

Além das comemoraçóes ao ano novo, o carnaval - tão culturalmente presente no Brasil - e que certamente será lembrado pelos alunos, mesmo os que não apreciam a festa, é outro componente cultural trabalhado na unidade. Na mesma perspectiva, essa festa é vista como elemento cultural em lugares como em Calnali (México), onde se converte como uma das celebraçóes mais importantes deste povoado mexicano. Além disso, a unidade ainda traz o carnaval típico de Cotabambas - Peru - festa trazida e imposta pelos espanhóis, mas que ganhou uma identidade própria da regiáo. Na mesma unidade ainda aparecem referências a um costume andino para a Semana Santa; e as celebrações de Natal na Venezuela e na Argentina.

Foco B: identidades culturais dos personagens.

Após as oportunas consideraçóes, iniciaremos, de forma objetiva, a análise de um dos textos que está presente em uma das unidades do livro El Arte de leer Español, aparecendo na primeira unidade, denominada Identidad, ilustrada com uma foto e associada ao texto escrito. A imagem, intitulado Será por eso que lo quiero tanto, publicado, originalmente, pela Viva, Revista Clarín, em 21/11/04, nos coloca em contato com a história de vida de duas irmãs esportistas: Serena e Vênus Williams. Serena, campeã pelo campeonato 
de US Open 99 e Vênus, Wimbledon, 2000. Além de mostrar o êxito das irmãs, o texto reforça o papel da família, na figura do pai, no sucesso das filhas. A escolha pela presença de uma família negra num LD de língua estrangeira, para nós, configura-se como um posicionamento ideológico não encontrado comumente nos LD de espanhol. Salvo alguns casos esporádicos, não é comum a presença deste grupo étnico nas páginas de um livro didático, principalmente quando relembramos que, na maioria deles, o referencial de família é quase sempre o europeu, da Espanha. Além disso, devemos considerar que, para um livro que não está carregado de imagens de pessoas, o negro aparece em pelo menos mais três outras unidades. Vejamos mais uma ocorrência:

A imagem que aparece na unidade 12, Fiestas y tradiciones, aparece novamente, a figura do negro na condição de um vencedor, aqui um capoeirista baiano, reconhecido e sua mulher - que não é negra - grávida e argentina; são personagens representativos de uma nova ordem social nas identidades étnicas e a possibilidade de inclusão de casamentos inter-étnicos, fatos esses que também não são comumente tratados nos $\mathrm{LD}$ de E/LE.

Ao lado da imagem do casal, aparece também a fotografia de uma colombiana, professora universitária que, por razões de estudos, vive agora na Argentina. São essas realidades táo diversas que retratam identidades igualmente múltiplas que se fazem presente no livro El arte de leer Español.

Ainda sobre esta condição da mulher (e do homem) no século XXI, o texto da p. 17 - unidade 1 - convida o aluno brasileiro a pensar em questóes referentes ao papel do homem e da mulher na família e, mais especificamente, em casa. Diante da questão “¿Como ves el cambio en la función estricta de padre y madre?”. O aluno, aprendiz de espanhol, é convidado a pensar nas relaçóes de gênero que predominam na sociedade contemporânea, além de avaliar as possíveis transformaçóes nos papéis sociais.

Portanto, através desses exemplos que marcam a discussão do ensino-aprendizado da língua espanhola no tocante à identidade, percebe-se que nela se discute bastante a questấo da língua como marca identitária do indivíduo. É possível observar que as atividades apresentadas nesta unidade não se limitam a informar aos estudantes onde se fala espanhol, por exemplo, mas, além disso, elas promovem uma interação entre este novo universo que é mostrado ao aluno e a própria formação identitária dele como brasileiro. Dessa forma, mesmo se tratando de um material cuja finalidade é mostrar elementos da e na língua espanhola, relacionando-a com sua (s) cultura (s) e diversidades culturais, entre mais de vinte países falantes do espanhol com sua história e identidade linguística e cultural, há espaço para se pensar na língua e na cultura brasileira e suas múltiplas relaçóes interculturais. 


\section{Segundo Enfoque - Síntesis: Curso de Lengua Española}

Foco A: espaços geográficos e territórios culturais.

A princípio, o livro Sintesis: curso de lengua española, traz consigo os aspectos relativos ao universo geográfico-cultural do povo hispânico, que são apresentados apenas em caráter informativo, podendo reforçar estereótipos e que em nada estimulam o olhar crítico dos alunos em torno dos elementos culturais apresentados.

É carregado de diálogos produzidos para atender ao objetivo e ao tema de cada uma das unidades didáticas. No que se refere aos espaços geográficos e aos territórios culturais, percebemos que há uma tendência muito forte em marcar os diálogos com situaçóes que se passam na Espanha, a maioria delas em Madri. Outro aspecto que nos ajuda a analisar a predominância desse espaço é o fato de que as marcas linguísticas com que são produzidos esses diálogos são também caracterizadas pela variante peninsular de Madri. Embora em alguns momentos apareçam textos que nos remetam ao universo hispânico americano, esses textos náo são explorados e o aluno sequer é levado a refletir sobre este aspecto.

As propostas sobre compreensão-interpretação dos textos apresentados, não têm como meta analisar esse outro espaço no qual a língua espanhola é também instrumento de interação, mas, com pretexto de trabalhar apenas a gramática, em detrimento dos aspectos geográficos e territórios culturais que deveriam ser explorados.

Outra unidade que tomamos como análise para verificar de que forma este livro contempla a pluralidade cultural do mundo hispânico é a vigésima primeira, intitulada “¿Te gusta el arte?". A presença desta unidade em si no livro didático já nos revela que a ideia de arte parece ser ainda tratada de forma equivocada ou até mesmo limitada. Que arte é esta? Quem são os artistas? Que arte é representada? Embora na introdução apareçam telas de pintores famosos de diferentes nacionalidades, durante toda a unidade, incluindo um diálogo apresentado, a referência que se faz é a pintores espanhóis, como por exemplo, Pablo Picasso e Diego Velázquez. Dando continuidade à unidade didática, encontramos uma atividade na seção Para oír y comprender, através da qual o aluno é motivado a, após ouvir uma gravação, identificar os títulos das obras de Juan Miro, Francisco de Goya e, mais uma vez, Pablo Picasso. Esta unidade, da forma como se apresenta, infelizmente, deixa clara a supremacia de um espaço hegemônico - Espanha além de representar um território cultural limitadíssimo quando aborda apenas a pintura ao falar em arte. Longe de nossas intençóes relegar o valor que esta expressáo artística tem, mas defendemos a ideia de que, se esta expressão artística foi a escolhida para trabalhar, poderiam ter sido exploradas as obras de outros grandes pintores do universo hispânico, como os grandes Diego Rivera, Frida Kahlo, dentre outros, não necessariamente provenientes da Espanha.

A partir das considerações que aqui foram feitas, é pertinente destacar que analisar o livro Síntesis: curso de lengua española, principalmente no que tange aos espaços geográficos e territórios culturais, é poder ter a convicção de que, apesar das intençôes 
colocadas na apresentação do livro, principalmente no que se refere à pluralidade cultural, o material em si, nas unidades que apresenta, náo consegue corresponder às possíveis expectativas criadas.

Foco B: identidades culturais dos personagens.

$\mathrm{Na}$ primeira unidade didática do livro, intitulada ¿Quién soy yo? ¿Quién eres tú?, iniciada na página 9 , o livro apresenta dois textos em que aparecem duas personagens anônimas: uma estudante de Recife que mora em Cali, na Colômbia; e um espanhol, de Barcelona, que mora no Rio de Janeiro, que estuda português e trabalha como vendedor de roupas numa loja. Os textos são apresentados ao aluno no intuito de trabalhar com estruturas próprias de sentenças em que o objetivo é apresentar-se, pois, não se discute acerca das identidades destes personagens, mas pede-se para que os alunos identifiquem os verbos que aparecem em cada um desses textos. Ainda vale destacar que em apenas duas ocorrências no livro aparecem fotografias referentes a personagens da vida real, embora anônimos. Na maioria das vezes, os personagens são representados em desenhos para ilustração dos diálogos que fazem parte do livro. Assim grande parte desses diálogos é composta por personagens fictícios cujos padrôes de conversação que geralmente estão voltados a trabalhar com questōes estruturais da língua.

No que se refere aos personagens famosos que são encontrados ou aos quais se faz referência neste livro, é impressionante a ênfase dada às personalidades ligadas à literatura, na sua maioria, espanhóis. Esses personagens famosos são mostrados ao final de cada texto, onde o livro coloca uma pequena biografia deles. Devemos também considerar que um expressivo número desses autores é de homens, o que revela que o livro, mesmo explorando a literatura e seus representantes enquanto manifestação cultural faz mínima referência à figura feminina.

Diante do exposto, dois aspectos nos inquietam: primeiro o fato deste livro, pela própria concepção de língua que traz subjacente nas suas unidades, limita bastante a nossa capacidade de análise; segundo, que este material ainda preserve e reforce uma ideia de cultura e de identidades ainda táo hegemônicas. No que se refere à segunda inquietação, acreditamos ser oportuno colocar que o livro aqui analisado se limita a trazer quase sempre identidades representadas por homens, espanhóis, artistas consagrados ou anônimos que, na maioria das vezes, são professores, alunos, advogados, engenheiros, e tudo que revela o modelo de sociedade / identidade estrutural que aparentemente tem identidade estável, reproduzindo os padróes sociais de bem-estar e possuidoras de poder econômicos e hierárquicos diferenciados.

Sendo assim, diante das reflexóes aqui postas, percebemos que o livro Sintesis: curso de lengua española, ao contrário do que defende na sua apresentação, não promove, por meio de suas atividades, nenhuma forma de interaçáo entre as culturas que estáo em contato no processo de aprendizagem do espanhol pelo aluno brasileiro. Atividades que apenas buscam trabalhar aspectos gramaticais, de tradução e decodificação com pouca reflexão acerca do outro e de si estão aquém de uma abordagem intercultural no ensino de línguas. 


\section{Considerações finais}

Depois de termos trilhado um universo diverso, amplo de informaçóes e concepçóes, apresentamos o alcance de nossas possíveis conclusóes, que somadas a outras reflexóes, constituirá efetivamente as abordagens que configuram a identidade e pluralidade cultural nos livros didáticos de espanhol para brasileiros, através de suas peculiaridades e formas de focar o ensino da língua espanhola para esse fim.

Portanto, nossa investigação, até o presente momento, pôde perceber que o livro Sintesis: curso de lengua española, pelo que analisamos através dos textos selecionados, não trabalha, de fato, com a multiplicidade de espaços geográficos e territórios culturais que constituem o universo hispânico. Vale ressaltar que o livro, exceto quando tem a intenção de mostrar algumas particularidades, sobretudo linguísticas do espanhol da América, não explora este continente como lugar onde a língua espanhola é ferramenta de interação linguística e manifestação cultural.

Em diferente abordagem ao livro anteriormente citado, o El arte de ler Español, apresenta uma concepção de espaço e de território bastante contemporânea, pois, ao contrário até mesmo do que esperávamos, demonstra entender que, na contemporaneidade, os espaços são cada vez mais flexíveis, imprecisos e permeáveis, surpreendendo nossas expectativas, até mesmo pelo que conhecemos dos LD que estáo em circulação.

Ao tratar de temas que se organizam em prol da possibilidade de se estabelecer, na prática educativa, uma relação entre aprender os conhecimentos inerentes a cada cultura, aprendendo sobre a realidade delas e as questōes da vida real e de suas transformaçóes na contemporaneidade, os aborda não apenas considerando os diversos contextos hispânicos, mas também traz estes temas para outras realidades como, por exemplo, a do Brasil e dos Estados Unidos.

O livro El arte de leer Español tem uma concepção singular sobre a compreensão de fronteiras espaciais e territoriais na contemporaneidade. Enquanto que o livro Sintesis: curso de lengua española, na maioria das unidades, limita seu universo às realidades contextuais da Espanha (de Madri). O El arte de leer Español rompe as barreiras do mundo hispânico e vai demonstrar que hoje, apesar dos traços culturais distintivos, os mundos estão interconectados e não se pode falar em Espanha, Argentina ou México sem também se falar em outros territórios que estão sendo resinificados e inter-relacionados constantemente. Como falar de América Latina e não falar em Brasil, embora seja esse país um parêntese da língua portuguesa na América Espanhola?

No tocante às identidades que circulam nestes livros, tivemos como objetivo analisar que personagens [famosos e anônimos] marcam presença no material didático selecionado. Similar ao que acontece aos espaços e territórios corroboramos com a ideia de que, atualmente, as identidades encontram-se fragmentadas e que, nas possíveis relaçôes que podem ser estabelecidas, essas identidades estão em constante processo de reconfiguraçáo. Para tanto, embora não tenha sido do nosso interesse de pesquisa 
promover uma discussão específica sobre etnia, gênero ou classe social, por exemplo, esses elementos foram tomados como referência para podermos, de alguma forma, identificar as vozes identitárias que circulam nestes LD.

É oportuna ainda a lembrança de que, embutida nessas categorias, também estaria inserida a análise acerca da afirmação das identidades latino-americanas por parte dos livros em análise. O livro Síntesis: curso de lengua española, é marcado pelo grande número de personagens anônimos, representados em forma de desenhos, criados para atender às necessidades comunicativas das unidades didáticas. $\mathrm{Na}$ maioria dos casos, esses personagens são oriundos da Espanha - dedução feita a partir dos contextos dos diálogos - e, quase sempre são professores, estudantes, diretores, advogados, engenheiros; personagens que certamente não representam a multiplicidade e diversidade identitária presentes na sociedade como um todo.

Os temas que envolvem a vida desses personagens tendem a não apresentar conflitos sociais, étnicos, de gênero, ou qualquer outro com o qual pudesse ser gerada alguma discussão mais crítica, ou mesmo que provocasse no aluno brasileiro uma atitude de auto percepçáo enquanto cidadão. Os personagens famosos que circulam nas 25 unidades deste livro são, na maioria das vezes, homens ligados à literatura ou outra expressão artística, muitos deles de origem espanhola. Em raros momentos o livro permite que o aluno brasileiro se perceba nessas relaçóes identitárias e, quando promove isso, por exemplo, é na condição de membro de uma sociedade que, diferentemente das demais apresentadas no livro, não respeita o direito das crianças e dos adolescentes, como pudemos constata no que foi apresentado no capítulo anterior. Ademais, é pertinente também ressaltar que o livro não tem nenhuma pretensão concreta de explorar as identidades latino-americanas que podem ser representadas em alguns dos personagens famosos que aparecem no material.

Diante de tudo aqui posto durante o processo da pesquisa e a escrita desse artigo, esperamos ter contribuído para a compreensão do papel do LD no ensino de LE, bem como ampliado as reflexôes acerca do tratamento às questôes culturais e identitárias no ensino de ELE, oferecendo a comunidade acadêmica e científica, elementos que poderáo contribuir para a prática de análise de LD produzidos no Brasil com a finalidade do ensino-aprendizagem de LE e, ao mesmo tempo, levando a cada cidadão ao conhecimento e apropriação crítica diante das decisóes acertadas sobre o papel social do material didático nas aulas de línguas.

\section{IDENTITY AND CULTURAL PLURALITY IN SPANISH TEXTBOOKS PRODUCED IN BRAZIL AND SELECTED BY PNLD - NATIONAL PROGRAMME OF TEXTBOOK}

- ABSTRACT: This article aims to promote, given the current reality, in which it sets up a scenario marked by breaking cultural boundaries and understand the world as a more unified universe, reflect on existing conceptions of culture in this context. The world increasingly marked by 
multicultural societies, the weakening of old cultural references and the multiplication of identity statements. The teaching of foreign languages is an opportunity to place the student in planetary universe of an apparent online culture, but which increasingly reinforces different identities. In this sense, the article presented here, and promote space for a discussion of these very contemporary issues, presents the analysis of a survey of two of the four textbooks in Spanish, selected to join the National Book Program for Education East, delimiting the choice of the characteristics of space and time for analysis and construction of this writing: El arte de leer Spanish and Sintesis: course española language. Not the total analysis of the books will be presented, opting to make a cut, taking as a criterion some teaching units and activities more targeted to the theme proposed, in addition to meet the rules and brevity of this article. Such research revolved around the following questions: How do the textbooks for the teaching and learning of Spanish produced in Brazil include: a) the cultural diversity of the Hispanic world? ; b) the claim - with respect to their community in training and socializing (s) of identity (s) American latina-(s)?; and c) interaction proposal from learning strategies, with the identity formation of the Brazilian student? Therefore, we adopted the methodology of qualitative analysis and content analysis technique, taking as indicators the following categories: geographical areas and cultural areas explored in the texts; the identities of anonymous characters and famous circulating in the books; and educational activities related to cultural issues proposed to the students. From the analysis it can be concluded that the selected books give different answers to the questions proposed for this research. The book Síntesis: lengua española course, does not explore, in fact, the cultural diversity of the Hispanic world; has its characters marked by non-Latin American identities and do not promote through activities related to cultural issues, no interaction with the identity formation of the Brazilian student. While the book El arte de leer Español explores the variety of geographical areas and cultural territories of the Hispanic world, and bring references from Brazil and elsewhere. In addition, the book prioritizes Latin American identities and promotes in many activities, interaction with the cultures and identities of the Brazilian learners of Spanish.

- KEYWORDS: Spanish foreign language. Identity. Cultural diversity. Textbook.

\section{REFERÊNCIAS}

ALMEIDA FILHO. J. C. P. Dimensóes comunicativas no ensino de línguas. São Paulo: Pontes, 2002.

BRASIL. Lei no 11.161, de 05 de agosto de 2005. Dispóe sobre o ensino da língua espanhola. Diário Oficial da Uniáo, Brasília, n. 151, 08 ago. 2005. Seção 1. p. 1.

CORACINI, M. J. Identidade e discurso. Campinas: Ed. da UNICAMP, 2003.

CORACINI, M. J. Língua materna-estrangeira: entre saber e conhecer. In: CORACINI, M. J. (Org.). A celebraçáo do outro: arquivo, memória e identidade. Campinas: Ed. da UNICAMP, 2007. p. 149-162. 
HALL, S. Identidades culturais na pós-modernidade. 10. ed. Rio de Janeiro: DE\&A, 2005. MARTÍN, I. R. Síntesis: curso de lengua española. São Paulo: Ática, 2005. Livro do professor. NASCIMENTO, D. M. Metodologia do trabalho científico: teoria e prática. Rio de Janeiro: Forense, 2002.

ORTIZ, R. Mundializaçáo e cultura. São Paulo: Brasiliense, 1994.

PICANÇO, D. C. L.; VILLABA, T. K. B. El arte de leer Español: ensino médio. Curitiba: Base Editora, 2006.

SILVA, T. T. A produção social da identidade e da diferença. In: SILVA, T. T. da.; HALL, S.; WOODWARD, K. (Org.). Identidade e diferença: a perspectiva dos estudos culturais. Petrópolis: Vozes, 2000. p. 73-102.

TILIO, R. C. O livro didático de inglês em uma abordagem sóciodiscursiva: culturas, identidades e pós-modernidade. Rio de Janeiro: PUC-Rio, 2006.

WOODWARD, K. Identidade e diferença: uma introdução teórica e conceitual. In: SILVA, T. T. da.; HALL, S.; WOODWARD, K. (Org.). Identidade e diferença: a perspectiva dos estudos culturais. Petrópolis: Vozes, 2000. p. 7-72.

Recebido em abril de 2016

Aprovado em agosto de 2016 
